\title{
(2) OPEN ACCESS \\ Family caregiver emotional distress in advanced cancer: the DME-C scale psychometric properties
}

\author{
Joaquín T Limonero (D) ,' Jorge Maté-Méndez (D) ,1,2 \\ María José Gómez-Romero (D) , 1,3 Dolors Mateo-Ortega (D) , 4 \\ Jesús González-Barboteo (1) , ${ }^{5}$ Montserrat Bernaus, ${ }^{6}$ \\ Montserrat López-Postigo, ${ }^{6}$ Agustina Sirgo, ${ }^{7}$ Silvia Viel, ${ }^{1,8}$ \\ Cruz Sánchez-Julve, ${ }^{9}$ Ramon Bayés, ${ }^{1}$ Xavier Gómez-Batiste (D) , ${ }^{10,11}$ \\ Joaquín Tomás-Sábado (D) ${ }^{12}$
}

\begin{abstract}
- Additional material is published online only. To view, please visit the journal online (http://dx.doi.org/10.1136/ bmjspcare-2020-002608).
\end{abstract}

For numbered affiliations see end of article.

\section{Correspondence to}

Professor Joaquín T Limonero, School of Psychology. Stress and Health Research Group, Universitat Autonoma de Barcelona Facultat de Psicologia, 08193 Bellaterra, Catalunya, Spain; joaquin.limonero@uab.cat

Received 28 July 2020 Revised 3 November 2020 Accepted 16 November 2020

\section{Check for updates}

(c) Author(s) (or their employer(s)) 2020. Re-use permitted under CC BY-NC. No commercial re-use. See rights and permissions. Published by BMJ.

To cite: Limonero JT, MatéMéndez J, Gómez-Romero MJ, et al. BMJ Supportive \& Palliative Care Epub ahead of print: [please include Day Month Year]. doi:10.1136/ bmjspcare-2020-002608

\section{ABSTRACT}

Background Family caregivers of patients with advanced illness at end of life often report high levels of emotional distress. To address this emotional distress is necessary to have adequate and reliable screening tools.

Aim This study analyses the psychometric properties and clinical utility of the Family Caregiver Emotional Detection Scale for caregivers of patients with end-stage cancer (DME-C, Spanish acronym) who are receiving palliative care (PC).

Design Multicentre, cross-sectional study. Settings/participants Family caregivers of patients with advanced cancer at end of life receiving palliative treatment were interviewed to explore their emotional distress through the DME-C scale and other instruments measuring anxiety and depression (Hospital Anxiety and Depression Scale (HADS)), distress thermometer (DT) and overload (B), as well as a clinical psychological assessment (CPA).

Results 138 family caregivers, 85 (61.6\%) female and 53 (38.4\%) male, with an average age of $59.69 \pm 13.3$ participated in the study. The reliability of the scale, as measured by Cronbach's alpha, was 0.76 , and its stability over time was 0.734 . Positive, significant correlations were found between the DME-C and the scores for anxiety and depression registered on the HADS scale, as well as with the total result of this latter scale and the results for $B$, the DT and the CPA. A statistical analysis of the receiveroperating characteristic curves showed that the scale has a sensitivity and specificity of $75 \%$, and that the cut-off point for the detection of emotional distress was a score $\geq 11$. Fifty-four per cent of the caregivers displayed emotional distress according to this scale.
Conclusions The DME-C displays good psychometric properties. It is simple, short, reliable and easy to administer. We believe that the instrument is useful for the detection of emotional distress in the family caregivers of hospitalised patients suffering from end-stage illnesses and receiving PC.

\section{INTRODUCTION}

The family members of patients suffering from advanced illnesses and nearing the end of their lives often feel threatened or powerless as they face the inevitability of loss. ${ }^{1}$ They can sometimes experience high degrees of emotional distress. ${ }^{2}$ Family members serve as the main source of emotional support for these end-stage patients, as they tend to be the main providers of both practical and emotional care, and a special burden is often placed on the family caregiver. ${ }^{3}$ Most caregivers feel unprepared for their role, they do not have the experience to manage the patient, the illness or related practical issues including one's own emotions or those of patients or other family members. ${ }^{4}$ Aspects related to psychological variables, as well-being or anxiety, have a high influence in the burden of care at end-of-life situations. ${ }^{5}$ According to the studies, these aspects influence the degree of emotional distress caregivers experience that ranges between $25 \%$ and $65 \%$ depending on studies or scales of measures used. ${ }^{1}$

To ensure that family members are fully able to care for these patients, there is a need for early detection of any sources of real, imagined and/or potential suffering of patients and their families. It is also 
vital to identify their most pressing concerns, needs, priorities and preferences. ${ }^{67}$ In the field of palliative care (PC), the family caregiver (also called the primary or informal caregiver) is the family member (partner, child, sibling or other relatives) or friend who accompanies and cares for the patient at a PC unit or service, spending a large proportion of his or her time offering this care without receiving any economic compensation in exchange. These caregivers have a significant emotional bond with the patient and tend to play key roles in ensuring the reorganisation, maintenance and cohesiveness of their families during this period ${ }^{8}$ providing emotional and practical assistance. ${ }^{9}$

Wittenberg-Lyles et $a l^{10}$ found that when such family members are worried and display significant levels of emotional distress and suffering, the patients themselves are likely to experience greater suffering as well. This phenomenon, called 'reciprocal suffering', has negative consequences for the patient's overall wellbeing. The National Institute of Clinical Excellence $(\mathrm{NICE})^{11}$ guidelines on how to improve PC emphasise the need to provide both caregivers and their families with sources of information, support and advice. These resources help them carry out their caregiving tasks, and they act as a preventive factor against emotional distress and while facilitating the processes of emotional adjustment and adaptation both during the illness itself and in the subsequent mourning period. In the context of caring for a loved one with an advanced illness, it is hardly surprising that family caregivers tend to display emotional distress and suffering. These caregivers face extreme experiences that come with a high degree of emotional impact and with the significant difficulties inherent in adapting to rapidly changing and evolving situations that place great demands on their resources. ${ }^{1712}$

The 'Threats-Resources' model created by Bayés et $a l^{13}$ can be applied to both patients and caregivers. According to this model, the caregiver tend to suffer when they experience internal and/or external symptoms that they view as threatening to their physical and/or psychological health, and when they feel they lack the resources to deal with these symptoms or that the resources at their disposal cannot effectively reduce the potential threat. They experience feelings of impotence when they cannot successfully confront these threats, resulting in suffering. This suffering on the part of caregivers is also subject to the positive or negative influence of the caregiver's mood. Later research broadened the scope of measurement of this phenomenon with the Integrated Suffering Model, ${ }^{14}$ which shows that caregivers tend to suffer when their coping strategies and regulation processes are dysfunctional or when the situation lasts for a long period, resulting in exhaustion. This is a dynamic situation, and conditions may vary along with the evolution of the patient's illness. The cases of terminally ill patients often evolve quite quickly, and the degree of suffering of caregivers can fluctuate along with the patient's changing circumstances. This mutability over time means that there is a need for reliable, practical and non-invasive instruments that can detect and monitor changes in the level of suffering to offer the best possible treatment.

Advanced illnesses, especially the processes before the end of a person's life, are complex situations, and in this context psychological research often faces obstacles $^{15}$ due to patients' vulnerability and fragility. Therefore, there is a need to develop specific instruments with good psychometric properties ${ }^{16}{ }^{17}$ that can analyse the suffering and needs of main caregivers. Some scales developed in other contexts have been used to assess depression or anxiety in caregivers, such as the Hospital Anxiety and Depression Scale (HADS). ${ }^{18}$ Other scales assess caregiver needs, more for epidemiological purposes than for detection or treatment, ${ }^{19}$ quality of life scales ${ }^{20}$ or resilience. ${ }^{21}$ However, in general, these scales are not specific to caregivers of patients receiving PC or are not adequate because they contain too many items that could add additional fatigue or discomfort to the caregiver. About caregiver overload, a large number of them have been developed, ${ }^{22}$ but they generally suffer from the same problems as the previous scales. ${ }^{23} 24$

This would address the lack of reliable measurement indicators in this area, often a barrier to expanding knowledge of the effectiveness of PC. In light of all of the above, and especially of this lack of instruments to gather information on emotional distress in the main caregivers of advanced and end-stage oncology patients, the research team had developed along similar lines to a previous measurement tool they had developed, but this time aimed at main caregivers. ${ }^{25-27}$ A description of the systematic process used to develop this scale to measure the emotional distress of family caregivers of patients with advanced and end-stage illnesses (Caregiver Emotional Detection Scale (DMEC)), as well as the scale's components, can be found in Limonero et al. ${ }^{28}$ Thus, the objectives of this study are (1) to assess the scale's psychometric properties, and (2) to confirm its clinical validity for screening and early identification of emotional distress in caregivers of patients with advanced or end-stage cancer.

\section{MATERIALS AND METHODS}

\section{Study design and setting}

In this multicentre, cross-sectional study, the DME-C scale was administered to caregivers of patients in four PC units in the Autonomous Region of Catalonia, Spain. The inclusion criteria called for participants who were: (1) over 18 years old; (2) main caregivers of oncology patients with advanced, end-stage cancer; (3) who had received care from a PC team; (4) were able to hold a conversation and answer the questions they were asked; and (5) participated voluntarily and signed informed consent. Excluded from the sample 
EVALUACIÓN DEL MALESTAR EMOCIONAL DEL CUIDADOR PRINCIPAL DEL PACIENTE CON ENFERMEDAD AVANZADA (DME-C)

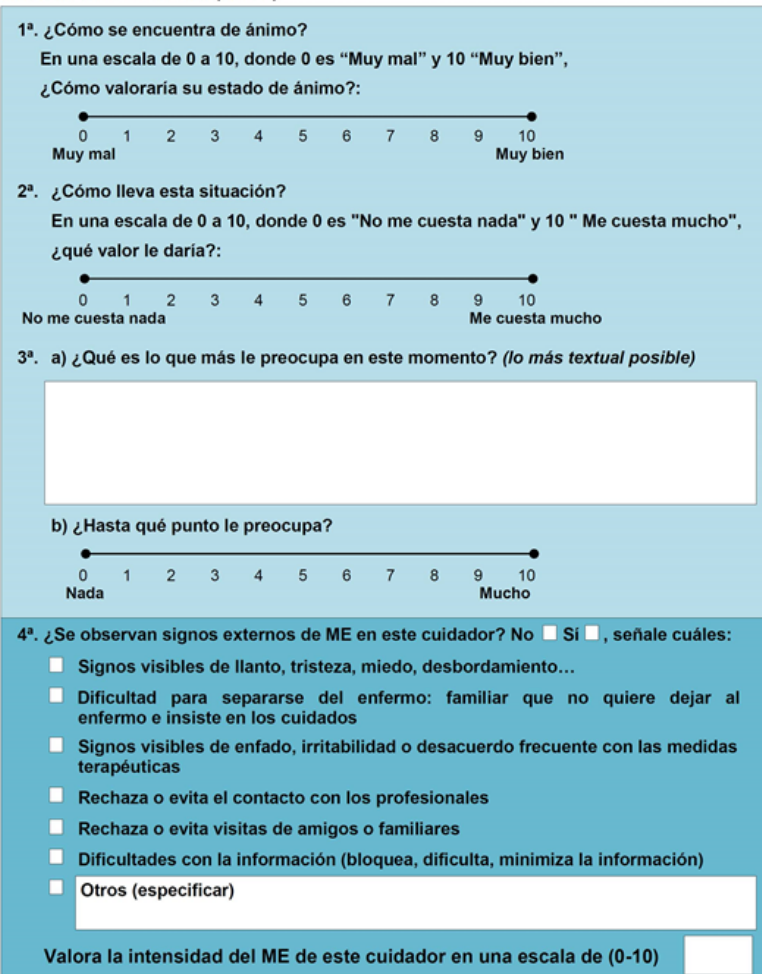

servaciones:

$$
\text { Observaciones: }
$$

CRITERIOS DE CORRECCIÓN - DME-C:

$(10-$ item 1$)+$ item $2 \Rightarrow[10-(\quad)]+()=$

Figure 1 Caregiver Emotional Distress Detection

Questionnaire (DME-C) administered to the main caregivers of patients with advanced or end-stage illness.

were those who did not meet these criteria, as well as some who did meet the criteria but were experiencing highly emotional situations as their family members were in the final days of their lives. The sample size was calculated to meet the criterion for recruiting participants according to the number of items of the instrument validated. In this sense, we follow the criteria of Gorsuch ${ }^{29}$ that suggests a ratio of five subjects for each item but never $<100$ subjects, and Boateng et $a l^{30}$ suggest a ratio of 10 per item. According to these recommendations, we used a convenience sample of 148 caregivers. Each PC unit recruited 37 caregivers. Thus, a convenience sample of 148 adults caregivers was invited to take part in the study. Of them, 8 (5.4\%) declined to participate in the study. Two participants were excluded due to incomplete assessment data, leaving a final sample of 138 caregivers.

\section{Measurement}

In addition to collecting data on variables related to the illness and sociodemographic variables, the researchers administered the following instruments:

Emotional Distress Detection Questionnaire for caregivers of patients with advanced, end-stage illnesses (DME-C) developed by Limonero et $a l^{28}$ which consists of two parts, one aimed at caregivers and another for healthcare professionals. The caregiver is asked to respond to two questions related to mood and the results of the process of adaptation to the situation of the illness of their family member. The questions are answered on a visual numerical scale from 0 to 10. Additionally, information is collected as to the presence or absence of worry and the intensity of this worry $(0-10)$. The second part of the scale is an observation tool for healthcare professionals, allowing them to record external signs of emotional distress in the caregiver. The professional registers the presence or absence of these signs and records their overall intensity $(0-10)$ (see figure 1 ). The DME-C yields a total score (0-20) made up of the sum of the scores on the items related to mood and coping. The questions on worries and external signs of emotional distress allow healthcare professionals to offer more specific care, and they validate the overall score for the DME-C.

To analyse the convergent validity of the DME-C, the following instruments were administered:

The Distress Thermometer (DT) created by Holland et $\mathrm{al}^{31}$ is a numerical scale consisting of a single item measuring the overall emotional distress experienced by the caregiver on a scale of $0-10$. The sensitivity values found for this instrument fluctuate between $75 \%$ and $80 \%$, and its specificity is about $60 \%$. According to the creators of the tool, scores $\geq 4$ indicate the presence of emotional distress

Hospital Anxiety and Depression Scale (HADS). ${ }^{18}$ This scale detects the presence of anxiety and depression in non-psychiatric hospital settings. It consists of 14 items presented in a four-point Likert-type format (range from 0 to 3). Seven of the items make up the anxiety subscale and the other seven measure depression. The maximum score for each subscale is 21 points, with scores obtained by adding up the points for the items, each of which corresponds to a symptom. The two subscales have been shown to have the same cutoff points, values that are generally between 8 and 10 . The internal consistency of the scale measured through Cronbach's alpha was 0.81 for the anxiety subscale and 0.83 for the depression subscale.

Abbreviated Zarit Scale on Perceived Caregiver Overload. ${ }^{32} \mathrm{~A}$ reduced seven-item scale with Likert-type questions for which respondents can choose among five possible answers (never-always). The instrument measures the extent to which family members of patients receiving PC feel overwhelmed. The tool explores feelings of overload, self-care and the loss of social or family roles. According to the authors, the test displays a sensitivity and specificity of $100 \%$, and scores $\geq 17$ indicate that the family is overwhelmed. The Cronbach's alpha for this study was 0.84 .

Clinical psychological interview. A psychologist with experience in PC conducted independent, semistructured interviews with the participants to assess their overall degree of emotional distress using a five-point Likert-type scale, where a score of 1 indicated 'no 
Table 2 Descriptive statistics

\begin{tabular}{|c|c|c|c|c|c|c|c|c|}
\hline & & $\begin{array}{l}\text { Overall score } \\
\text { DME-C }\end{array}$ & Zarit overload & $\begin{array}{l}\text { HADS anxiety } \\
\text { subscale score }\end{array}$ & $\begin{array}{l}\text { HADS depression } \\
\text { subscale score }\end{array}$ & $\begin{array}{l}\text { Overall HADS } \\
\text { score }\end{array}$ & $\begin{array}{l}\text { Overall } \\
\text { psychological } \\
\text { assessment }\end{array}$ & $\begin{array}{l}\text { Distress } \\
\text { thermometer }\end{array}$ \\
\hline $\begin{array}{l}\text { Mean (SD) } \\
\text { (CI 95\%) }\end{array}$ & & $\begin{array}{l}11.21(4.24) \\
(10.41-11.84)\end{array}$ & $\begin{array}{l}18.64(7.5) \\
(17.36-19.83)\end{array}$ & $\begin{array}{l}9.67(5.38) \\
(6.1-9.61)\end{array}$ & $\begin{array}{l}6.79(3.98) \\
(6.85-11.14)\end{array}$ & $\begin{array}{l}16.46(8.81) \\
(13.60-19.32)\end{array}$ & $\begin{array}{l}2.95(0.92) \\
(2.75-3.17)\end{array}$ & $\begin{array}{l}4.65(2.71) \\
(3.55-5.74)\end{array}$ \\
\hline \multirow[t]{3}{*}{ Percentile } & 25 & 9 & 13 & 5 & 4 & 9 & 2.00 & 3 \\
\hline & 50 & 11.00 & 17 & 10 & 7 & 16 & 3.00 & 5 \\
\hline & 75 & 14.00 & 23 & 14 & 9 & 22 & 4.00 & 8 \\
\hline
\end{tabular}

DME-C, Caregiver Emotional Distress Detection Questionnaire; HADS, Hospital Anxiety and Depression Scale.

distress' and five indicated 'severe emotional distress'. The duration of the interview was between 15 and 20 min.

The DME-C was administered by a doctor or nurse in the course of the first 3 days after the patient had been admitted to the PC unit. On the same day, and around the same time, the caregiver was visited by the psychologist, who conducted the semistructured interview and clinically assessed the caregiver's overall degree of emotional distress and administered the remaining instruments.

\section{Statistical analysis}

The data analysis was carried out using the software program Statistical Package for the Social Sciences (SPSS, V.25). Descriptive indices and intraclass correlation coefficients were calculated, and the $\chi^{2}$ test, nonparametric Kruskal-Wallis test was carried out. A receiver-operating characteristic (ROC) curve analysis was also carried out to determine the sensitivity and specificity of the scale. In all cases, statistical significance was set at $\mathrm{p}<0.05$.

\section{RESULTS}

\section{Descriptive data}

The final convenience sample was 138 caregivers (90 female and 48 male) with an average age of $59.69 \pm 13.3$ years. The most common relationship to the patient was that of a partner (65.2\%), followed by a child $(27.5 \%)$ (see table 1$)$.

\begin{tabular}{lc}
\hline Table 1 & \multicolumn{1}{l}{ Caregiver sociodemographic variables } \\
\hline Variable & $\mathrm{N}(\%)$ \\
\hline Gender & $85(61.6 \%)$ \\
\hline Female & $53(38.4 \%)$ \\
\hline Male & \\
\hline Relationship to patient & $90(65.2 \%)$ \\
\hline Spouse/partner & $38(27.5 \%)$ \\
\hline Child & $8(5.8 \%)$ \\
\hline Sibling & $2(1.5 \%)$ \\
\hline Other family member & $120(87 \%)$ \\
\hline Resides with patient? & $18(13 \%)$ \\
\hline Yes & Mean (SD) \\
\hline No & $59.69(13.3)$ \\
\hline Caregiver age (years) & \\
\hline
\end{tabular}

\section{Main results}

The caregivers recorded an average emotional distress score of $11.21 \pm 4.24$, and it was observed that about half of the caregivers registered scores $\geq 11$ points. To identify any difference in the prevalence of distress as a function of the hospital, the non-parametric KruskalWallis test was carried out $\left(\chi^{2}=6.52 ; d f=4 ; \mathrm{p}=0.089\right)$, with the results showing no variation between the PC units in the study.

Table 2 shows the descriptive data for the variables in the study. It displays the DT scores, the HADS subscale and overall scores, the scores on the abbreviated Zarit overload test and the results of the psychologist's clinical assessments.

\section{Internal consistency and test-retest reliability}

The reliability of the DME-C was calculated by measuring its internal consistency in the form of Cronbach's alpha, with a result of 0.76 . The stability of the measurement over time (test-retest reliability) was determined by calculating the intraclass correlation coefficient. This calculation made use of data collected from 37 of the 138 caregivers, with an average of 4 days elapsing between the two tests. The value obtained was $0.734(\mathrm{p}<0.01)$.

\section{Criterion validity}

The intraclass correlation coefficients indicate that the DME-C had a positive and significant correlation with all the variables analysed (overload, clinical psychological assessment, HADS and its subscales and the distress thermometer). The correlations ranged from 0.42 in the case of the psychological assessment to 0.598 in the case of the HADS depression subscale (table 3).

\section{Establishing the sensitivity and specificity of the DME-C through ROC curve analysis}

To establish the clinical utility of the DME-C, ROC curves were drawn to determine the optimal cut-off point for specificity and sensitivity and identify the threshold score for emotional distress on the scale. The curves also serve as visual representations of the test's balance between sensitivity and specificity. ${ }^{33}$

To calculate the specificity and sensitivity of the DME-C, in light of the lack of a pattern for comparison or of a gold standard test in the field of PC, the total score for the DME-C was compared with a 
Table 3 Matrix showing intraclass correlation coefficients between the scores on the DME-C, the Zarit overload scale, the overall HADS (T-HADS), the HADS subscales measuring anxiety (A-HADS) and depression (D-HADS), the psychological assessment (PA) and the distress thermometer (DT)

\begin{tabular}{|c|c|c|c|c|c|c|}
\hline & DIME-C & ZARIT & A-HADS & D-HADS & T-HADS & DT \\
\hline Zarit emotional overload & $0.510^{* *}$ & - & & & & \\
\hline HADS anxiety subscale score (A-HADS) & $0.584^{* *}$ & $0.656^{* *}$ & - & & - & \\
\hline HADS depression subscale score (D-HADS) & $0.598^{* *}$ & $0.490^{*}$ & $0.766^{* *}$ & - & & - \\
\hline Overall HADS score (HADS) & $0.513^{* *}$ & $0.554^{* *}$ & $0.846^{* *}$ & $0.817^{* *}$ & - & \\
\hline Distress thermometer (DT) & $0.580^{*}$ & $0.602^{* *}$ & $0.493^{*}$ & $0.475^{*}$ & $0.357^{* *}$ & - \\
\hline Overall psychological assessment (PA) & $0.427^{* *}$ & $0.588^{* *}$ & $0.596^{* *}$ & $0.548^{* *}$ & $0.365^{*}$ & $0.297^{*}$ \\
\hline
\end{tabular}

${ }^{*} \mathrm{p}<05 ;{ }^{* *} \mathrm{p}<0.01$.

HADS, Hospital Anxiety and Depression Scale.

combination of the scores recorded on the Zarit overload scale, the HADS scale (the overall score), the distress thermometer and the clinical psychological assessment.

A reference variable was created to determine the presence or absence of emotional distress in each participant. It was based on a combination of the threshold values of the HADS scale (HADS $\geq 17$ ), the distress thermometer $(\geq 4)$, the abbreviated Zarit scale $(\geq 17)$ and the psychological assessment. A comparison of the values of this variable with those recorded for the DME-C scale shows an area below the curve of $0.82(\mathrm{p}<0.01)$, with a CI at $95 \%$ of $0.767-0.897$ (see Figure 2). Thus, the diagnostic capacity of the DME-C was demonstrated and the cut-off point was established at a score of 11 on the instrument, as this was the point on the curve with the best relationship between sensitivity (the capacity to detect caregivers suffering from emotional distress) and specificity (the capacity

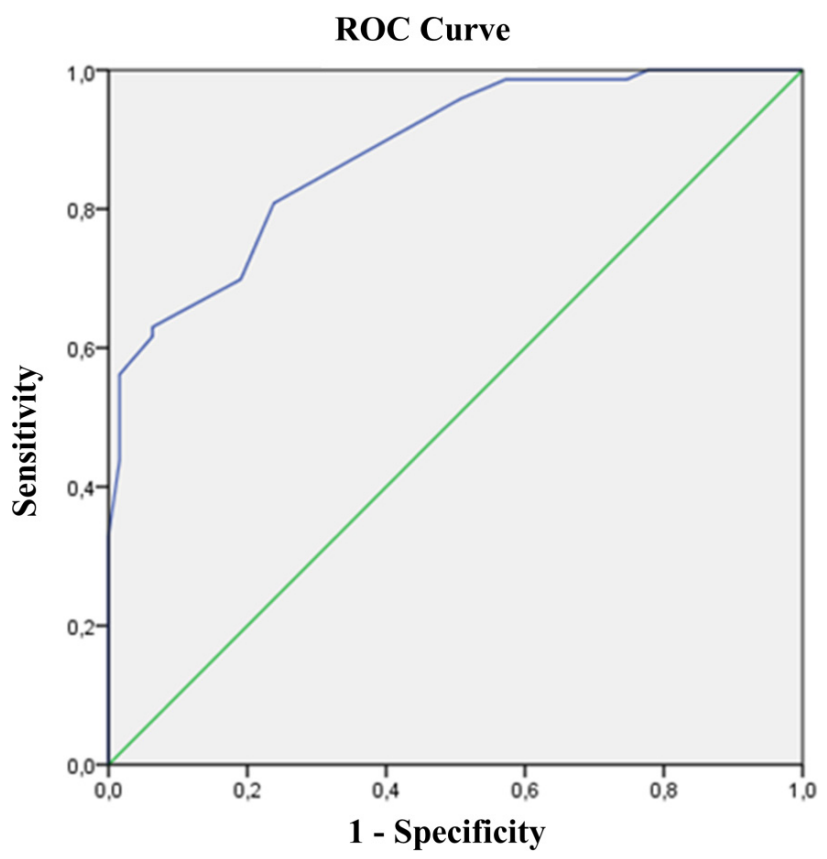

Figure 2 Receiver-operating characteristic (ROC) curve to determine the sensitivity-specificity of the overall score on the DME-C scale. to detect false positives). The figure for sensitivity at this point on the curve was $74.6 \%$, while the degree of specificity was calculated at $74.45 \%$. Caregivers scoring scores below 11, then, would be found not to be suffering from emotional distress, while those with scores $\geq 11$ would be above the threshold for such distress. Overall scores on the scale can range from 0 to 20. According to the cut-off figure established, 54\% of the caregivers displayed emotional distress.

The DME-C also observes the worries of caregivers. Of the caregivers in the study, $66 \%$ displayed worries related to emotional issues. The second most common kinds of worry were relateds to their relative's illness and the family (58\%) (see table 4). A comparison of the worries displayed by caregivers with emotional distress and those without emotional distress shows that only in the case of worried related to the illness (concerns over physical aspects related to the progression of the disease and the symptoms) were significant differences apparent, as these kinds of worries were more likely to affect caregivers with emotional distress than those without $\left(\chi^{2}=3.97 ; d f=1 ; \mathrm{p}<0.05\right)$. This type of worry also registered the highest degree of intensity. The analysis of the intensity of caregivers' concerns showed that worries about somatic issues had a strong correlation with the intensity of worries about family and emotional issues. Meanwhile, more intense worries about economic issues showed a positive correlation with family concerns.

The second part of the DME-C collects data on the presence of outward signs of emotional distress in the caregiver, as observed by a healthcare professional. The caregivers who had displayed emotional distress according to the first part of the instrument were more likely to show these external signs than those who had not $\left(\chi^{2}=6.5 ; d f=1 ; \mathrm{p}<0.01\right)$. The caregivers with emotional distress were more likely, to a statistically significant degree, to display 'visible signs of sadness, fear, crying, feeling overwhelmed' $\left(\chi^{2}=23.45 ; d f=1\right.$; $\mathrm{p}<0.001)$; 'difficulty in separating from the patient: the family refuses to leave the patient and insists on making healthcare decisions' $\left(\chi^{2}=17.22 ; d f=1\right.$; $\mathrm{p}<0.001)$; and 'visible signs of rage, irritability or disagreement with therapeutic measures' $\left(\chi^{2}=14.04\right.$; 


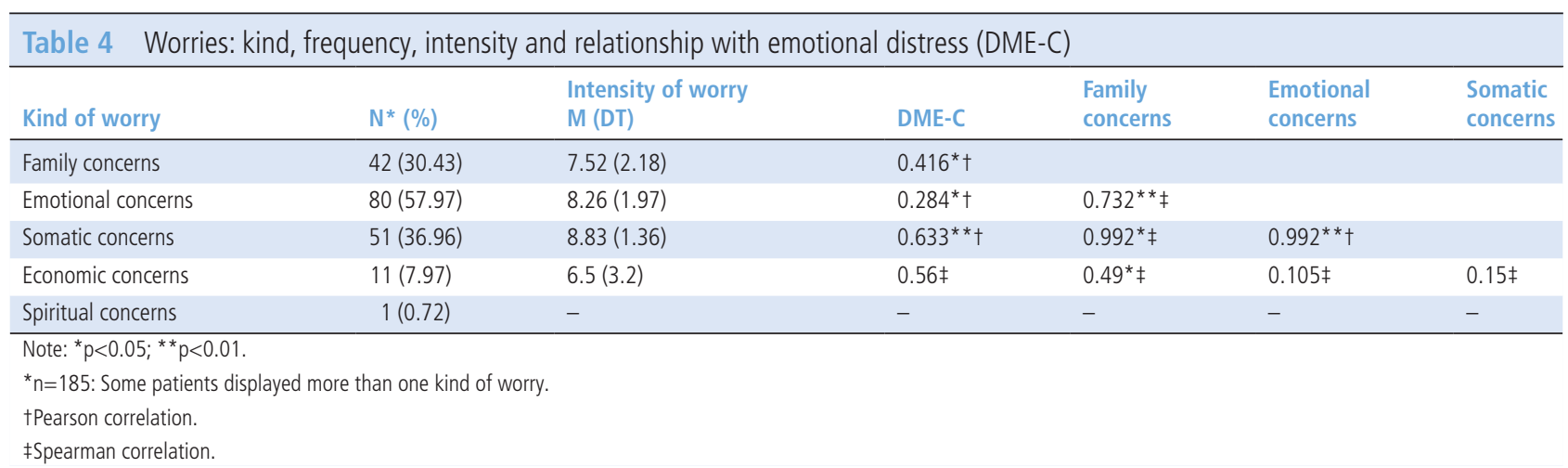

$d f=1 ; \mathrm{p}<0.001)$. No significant differences were found in the rest of the external signs assessed between caregivers with emotional distress and those without.

\section{DISCUSSION}

The main caregivers of patients with advanced or endstage illnesses tend to experience a large emotional burden, which can lead to emotional distress or suffering. ${ }^{1}$ To make possible early detection of caregiver suffering by healthcare professionals, it is necessary to have specific and easily applied screening instruments that offer a valid, reliable and clinically significant measurement of this distress. ${ }^{34} \mathrm{It}$ is only through such early detection that professionals can offer timely intervention and care to ease the suffering of caregivers.

The results of this study confirm the validity and reliability of the DME-C as a tool to screen for emotional suffering in caregivers of advanced stage oncology patients based on the theoretical framework previously commented of Bayés et $a l^{13}$ and Krikorian and Limonero. ${ }^{14}$ The internal consistency analysis, carried out via the calculation of Cronbach's alpha, yielded a value of 0.76 , indicating an acceptable degree of consistency, given that the test is basically made up of two items (mood and coping). Meanwhile, the stability of the results over time (test-retest reliability), as measured through the intraclass correlation coefficient after 4 days, was 0.734 , an acceptable degree of stability. The fact that the DME-C is a very short test, with only three items, represents an advantage, in that the instrument can be used repeatedly in longitudinal studies without causing fatigue in the caregivers. While this brevity does have the potential to detract from the test's internal consistency, the DME-C nonetheless has enough level of internal consistency and stability for a test with so few items. ${ }^{35}$

The validity analysis demonstrated that the scores on the DME-C exhibited the expected correlations with other measures, displaying positive and significant correlations with the caregivers' emotional overload, the overall HADS scale and its subscales (anxiety and depression), the distress thermometer and the psychological assessment. We can conclude that, in addition to its good psychometric properties, the DME-C examines issues of relevance to caregivers. In fact, the use of the scale could in and of itself have therapeutic value, as indicated by the expert caregivers who participated in the early stages of the scale's development and the prima facie validation phase. This has also been observed in the development of other scales. ${ }^{26} 27$

The applicability of the DME-C is further supported by the fact that it was administered to caregivers of a range of ages, of different genders and in different PC units. Despite this diversity, they did not experience any apparent difficulties in understanding and responding to the items, ${ }^{27}$ which is evidence in favour of expanding the use of the instrument.

Our results show that more than half of the caregivers were experiencing emotional distress, pointing to a need to address the sources of this distress and to better serve caregivers' needs. ${ }^{421}$ The fact that caregivers' psychosocial needs often change along with the evolution of the patients' illness highlights the need for instruments that can monitor these emotional dynamics, systematically record the changes that occur and respond to evolving needs. ${ }^{36}{ }^{37}$ Because it is brief, easy to understand, ethical and non-invasive, and because it measures aspects that caregivers recognise as important, the DME-C can be administered repeatedly. This opens up possibilities for longitudinal studies of emotional distress and analysis of the effects of healthcare to support caregivers.

Meanwhile, the data on caregivers' worries shed light on some specific aspects that could play a role in the emotional distress of caregivers and affect their psychosocial needs. This information could help identify warning signs that indicate a caregivers' need to be referred to a specialist, or on the contrary, identify their strengths and their relationship with their emotional state. $^{38}$

Finally, the DME-C assesses outward signs of emotional distress (behaviours and emotions), informing a more comprehensive assessment of the caregiver's emotional distress. Our data show that caregivers suffering from emotional distress are more likely to exhibit these external signs than those who are not. ${ }^{4}$ These signs are also easily identifiable and would be especially valuable in cases where caregivers experience emotional difficulties, as they offer an indirect measurement of their emotional distress. ${ }^{4}$ 


\section{Limitations}

Despite the importance of the findings here, this study has several limitations that merit consideration. The first is connected to the use of a convenience sample of caregivers of patients with advanced or end-stage illnesses at four different PC units. Nonetheless, the caregivers were representative of the respective centres, and the application of the scale at four different locations would seem to indicate that it can be easily implemented with a minimal amount of training for healthcare professionals and that it could be used in other contexts. Thus, based on experience with an emotional detection scale aimed at patients ${ }^{25} 26$ that is now being administered in homes, primary care centres and to chronic patients, we believe that the DME-C could also be applied in the same settings. The second limitation stems from the fact that this scale was administered to caregivers who were able to carry on a continuous conversation, meaning that its use with caregivers with communication problems has not been tested. However, given the scale's brevity and simplicity, as well as the additional observation of external signs of emotional distress, it would likely be a great resource to identify emotional distress in these caregivers. It is also worth noting that this scale assesses emotional distress in the family caregiver, not in the broader family, which in our cultural context tends to have a great deal of influence on the care, emotional state and well-being of the patient.

\section{Clinical implications}

Despite these limitations, this study confirms that the DME-C is a simple, reliable and valid instrument to detect emotional distress in the main caregiver (in our study, family caregivers). The fact that the scale does not lead to iatrogenesis could also help ensure its effectiveness at detecting emotional distress. The results of DME-C would allow the elaboration of strategies aimed at the early approach to the emotional distress of caregivers to make an early referral to a specific professional like a psychologist or social worker. It is a simple instrument with good psychometric properties, easy to administer and help any healthcare professional to carry out this evaluation. Helping ease the suffering of caregivers is an effective way to help patients themselves, as family caregivers are the principal source of patients' emotional support, regardless of the suffering the former experience as they witness the suffering of their loved ones. This scale could support caregivers in this important work.

\section{CONCLUSIONS}

The chief advantages of the DME-C over other scales are its brevity, reliability and understandability, as well as the fact that it does not place any additional burden on caregivers, as indicated by prior research to develop the scale, ${ }^{26}$ a study that also showed that all the caregivers found the scale suitable, understandable and useful.

This scale allows early screening of emotional distress and facilitates referral for specialised intervention based on the detected needs.

\section{Author affiliations}

${ }^{1}$ School of Psychology, Stress and Health Research Group, Universitat Autonoma de Barcelona, Bellaterra (Cerdanyola del Vallès), Catalunya, Spain

${ }^{2}$ Psycho-oncology Care Unit, Institut Catala d' Oncologia, L'Hospitalet de Llobregat, Barcelona, Spain

${ }^{3}$ Psychology Unit, Egarsat, Mutua Colaboradora con la Seguridad Social n 276, Terrassa, Barcelona, Spain

${ }^{4}$ Palliative Care Unit, Consorci Sanitari de Terrassa, Terrassa, Catalunya, Spain

${ }^{5}$ Palliative Care Unit, Institut Catala d' Oncologia, L'Hospitalet de Llobregat,

Barcelona, Spain

${ }^{6}$ Palliative Care Unit, Consorci Corporació Sanitària Parc Taulí de Sabadell,

Sabadell, Barcelona, Spain

${ }^{7}$ Psycho-oncology Unit, Oncology Department, University Hospital Sant Joan de Reus, Reus, Barcelona, Spain

${ }^{8}$ Member of the Group of Psychologists of the Catalan-Balearic Society for Palliative Care, Barcelona, Spain

${ }^{9}$ Palliative Care Unit, Sant Camil Hospital-Residence Foundation-Sant Pere de Ribes, Sant Pere de Ribes, Barcelona, Spain

${ }^{10}$ The 'Qualy' Observatory. WHO Collaborating Centre for Public Health Palliative Care Programmes, Institut Catala d' Oncologia, L'Hospitalet de Llobregat, Barcelona, Spain

${ }^{11}$ Chair of Palliative Care, University of Vic, Vic, Barcelona, Spain

${ }^{12}$ University of Gimbernat and Tomas Cerda School of Nursing, Sant Cugat del Vallés, Barcelona, Spain

Twitter Joaquín T Limonero @JTLimonero

Acknowledgements We would like to express our sincerest gratitude to all the caregivers of patients with advanced and end-stage cancer who have contributed with their participation in this study.

Contributors JTL, JM-M, DM and MJG-R designed the study. JM-M, DM, MJG-R, MB, ML-P, AS, SV and CS-J collected data. JTL, JM-M, RB and JT-S analysed data. JTL, JM-M, JG-B and XG-B interpreted results. JTL, JM-M and JG-B wrote the manuscript. All authors reviewed the manuscript.

Funding This research was carried out, thanks in part to grant PSI2017-85134-R from the Spanish Ministry of Economy and Competitiveness (MINECO).

Competing interests None declared.

Patient consent for publication Not required.

Ethics approval The research protocol was approved by each of the Ethics and Clinical Research Committees of the participating Health Centres (CSPT ref. 2014535; CSdT ref. 29042014; HUSJR ref. 140327/3 pro3; FHRSC ref. 14/23) and by the Ethics Committee of Animal and Human Research of the Universitat Autònoma of Barcelona. This research has adhered to Spanish Law 15/1999 governing the protection of personal data.

Provenance and peer review Not commissioned; externally peer reviewed.

Data availability statement All data relevant to the study are included in the article or uploaded as supplementary information.

Open access This is an open access article distributed in accordance with the Creative Commons Attribution Non Commercial (CC BY-NC 4.0) license, which permits others to distribute, remix, adapt, build upon this work noncommercially, and license their derivative works on different terms, provided the original work is properly cited, appropriate credit is given, any changes made indicated, and the use is noncommercial. See: http://creativecommons.org/licenses/by-nc/4. $0 /$.

\section{ORCID iDs}

Joaquín T Limonero http://orcid.org/0000-0003-0573-791X Jorge Maté-Méndez http://orcid.org/0000-0002-2385-3132

María José Gómez-Romero http://orcid.org/0000-0003-2488-

7649

Dolors Mateo-Ortega http://orcid.org/0000-0003-2726-7461 
Jesús González-Barboteo http://orcid.org/0000-0002-80952102

Xavier Gómez-Batiste http://orcid.org/0000-0002-4946-5947

Joaquín Tomás-Sábado http://orcid.org/0000-0002-7156-7843

\section{REFERENCES}

1 Palacio C, Krikorian A, Limonero JT. The influence of psychological factors on the burden of caregivers of patients with advanced cancer: Resiliency and caregiver burden. Palliat Support Care 2018;16:269-77.

2 Fujinami R, Sun V, Zachariah F, et al. Family caregivers' distress levels related to quality of life, burden, and preparedness. Psychooncology 2015;24:54-62.

3 World Health Organization. Palliative care. cancer control: knowledge into action. WHO guide for effective programmes. Geneva: World Health Organization, 2007.

4 Limonero JT, Maté-Méndez J, Mateo D, et al. Caregiver emotional distress: external open-behaviour signs. BMJ Support Palliat Care 2019. doi:10.1136/bmjspcare-2019-001774. [Epub ahead of print: 25 Jun 2019].

5 Toledano-Toledano F, Domínguez-Guedea MT. Psychosocial factors related with caregiver burden among families of children with chronic conditions. Biopsychosoc Med 2019;13:6.

6 Krikorian A, Limonero JT, Maté J. Suffering and distress at the end-of-life. Psychooncology 2012;21:799-808.

7 Astudillo W, Mendinueta C, Astudillo E. El síndrome del agotamiento en los cuidados paliativos.. In: Astudillo EW, Mendinueta C, Astudillo E, eds. Cuidados del enfermo en fase terminal y atención a su familia. 4 edn. Barañáin: EUNSA, 2002: 515-26.

8 Maté-Méndez J, González-Barboteo J, Calsina-Berna A, et al. The Institut Català d'Oncologia model of palliative care: an integrated and comprehensive framework to address the essential needs of patients with advanced cancer. J Palliat Care 2013;29:237-43.

9 Toledano-Toledano F, Moral de la Rubia J. Factors associated with anxiety in family caregivers of children with chronic diseases. Biopsychosoc Med 2018;12:1-10.

10 Wittenberg-Lyles E, Demiris G, Oliver DP, et al. Reciprocal suffering: caregiver concerns during hospice care. J Pain Symptom Manage 2011;41:383-93.

11 National Institute of Clinical Excellence (NICE). End of life care for adults: service delivery NICE Guide [NG142], 2019. Available: www.nice.org.uk/guidance/ng142 [Accessed 14 Jul 2020].

12 Limonero JT. Evaluación de necesidades y preocupaciones en enfermos en situación terminal. Revista de Psicología de la Salud 2001;13:63-77.

13 Bayés R, Arranz P, Barbero J, et al. Propuesta de un modelo integral para Una intervención terapéutica paliativa. Med Paliat 1996;3:114-21.

14 Krikorian A, Limonero JT. An integrated view of suffering in palliative care. J Palliat Care 2012;28:41-9.

15 Limonero JT, Gil-Moncayo F. Importance of psychological research in palliative care: barriers in its development. Palliat Med Hosp Care Open J 2014;1:1-3.

16 Hudson PL, Trauer T, Graham S, et al. A systematic review of instruments related to family caregivers of palliative care patients. Palliat Med 2010;24:656-68.

17 Aslakson R, SM D, Wilson RF, et al. Assessment tools for palliative care. Technical brief No. 30 AHRQ publication No. 14-17-EHC007-EF. Rockville, MD: Agency for Healthcare Research and Quality, May 2017. www.effectivehealthcare. ahrq.gov/reports/final.cfm

18 Tejero A, Guimera E, Farré JM, et al. Uso clínico del HADS (Hospital anxiety and depression scale) en población psiquiátrica: un estudio de su sensibilidad, fiabilidad y validez. Rev Depto Psiquiatría Facultad de Med Barna 1986;13:233-8.
19 Lefranc A, Pérol D, Plantier M, et al. Assessment of informal caregiver's needs by self-administered instruments: a literature review. Eur J Public Health 2017;27:796-801.

20 Weitzner MA, Jacobsen PB, Wagner $\mathrm{H}$, et al. The caregiver quality of life Index-Cancer (CQOLC) scale: development and validation of an instrument to measure quality of life of the family caregiver of patients with cancer. Qual Life Res 1999;8:55-63.

21 Palacio G C, Krikorian A, Gómez-Romero MJ, et al. Resilience in caregivers: a systematic review. Am J Hosp Palliat Care 2020;37:648-58.

22 Cooper B, Kinsella GJ, Picton C. Development and initial validation of a family appraisal of caregiving questionnaire for palliative care. Psychooncology 2006;15:613-22.

23 Deeken JF, Taylor KL, Mangan P, et al. Care for the caregivers: a review of self-report instruments developed to measure the burden, needs, and quality of life of informal caregivers. J Pain Symptom Manage 2003;26:922-53.

24 Kinsella G, Cooper B, Picton C, et al. A review of the measurement of caregiver and family burden in palliative care. J Palliat Care 1998;14:37-45.

25 Maté J, Mateo D, Bayés R, et al. Elaboración y propuesta de un instrumento para la detección de malestar emocional en enfermos al final de la vida. Psicooncología 2009;6:507-18.

26 Limonero JT, Mateo D, Maté-Méndez J, et al. Evaluación de las propiedades psicométricas del cuestionario de Detección de Malestar Emocional (DME) en pacientes oncológicos. Gaceta Sanitaria 2012;26:145-52.

27 Viel S, Limonero JT, Maté J, et al. Evaluación de las propiedades psicométricas de la Escala de Detección de la Soledad Existencial en pacientes con enfermedades avanzadas. Psicooncología 2019;16:161-76.

28 Limonero JT, Maté J, Mateo D, et al. Una escala para la detección del malestar emocional de los cuidadores principales de personas con enfermedad avanzada o al final de la vida. Ansiedad y Estrés 2016;22:104-9.

29 Gorsuch RL, Analysis EF. Handbook of multivariate experimental psychology. Boston, MA: Springer US, 1988: 231-58.

30 Boateng GO, Neilands TB, Frongillo EA, et al. Best practices for developing and validating scales for health, social, and behavioral research: a primer. Front Public Health 2018;6:149.

31 Holland JC, Andersen B, Breitbart WS, et al. The NCCN distress management clinical practice guidelines in oncology. $J$ Natl Compr Canc Netw 2010;8:448-85.

32 Gort AM, March J, Gómez X, et al. Escala de Zarit reducida en cuidados paliativos. Medicina Clínica 2005;124:651-3.

33 Burgueño MJ, García-Bastos JL, González-Buitrago JM. Las curvas ROC en la evaluación de las pruebas diagnósticas. Med Clin 1995;104:661-70.

34 Andersen BL, DeRubeis RJ, Berman BS, et al. Screening, assessment, and care of anxiety and depressive symptoms in adults with cancer: an American Society of clinical oncology guideline adaptation. J Clin Oncol 2014;32:1605-19.

35 Green SB, Yang Y, Alt M, et al. Use of internal consistency coefficients for estimating reliability of experimental task scores. Psychon Bull Rev 2016;23:750-63.

36 Mateo-Ortega D, Gómez-Batiste X, Maté J, et al. Effectiveness of psychosocial interventions in complex palliative care patients: a quasi-experimental, prospective, multicenter study. $J$ Palliat Med 2018;21:802-8.

37 Sutanto LL, Ying FM, Agarwal A, et al. A scoping review of psychosocial interventions for informal caregivers of palliative cancer patients. J Pain Manag 2017;10:23-30.

38 Palacio C, Limonero JT. The relationship between the positive aspects of caring and the personal growth of caregivers of patients with advanced oncological illness: Postraumattic growth and caregiver. Support Care Cancer 2020;28:3007-13. 